\title{
Ameliorative Influence of Dietary Dates on Doxorubicin-Induced Cardiac Toxicity
}

\author{
Ashraf Nabiel Abdalla', Waleed Hassan Almaliki', Mohammed Hasan Mukhtar ${ }^{2}$, \\ Firoz Anwar ${ }^{3}$, Imran Shahid ${ }^{*}$, Salah Ali Menshawi ${ }^{4}$, Tagreed Sadeek Alsulimani ${ }^{5}$ \\ ${ }^{1}$ Department of Pharmacology and Toxicology, College of Pharmacy, Umm Al Qura University, Makkah, \\ Saudi Arabia \\ ${ }^{2}$ Department of Biochemistry, Faculty of Medicine, Umm Al Qura University, Makkah, Saudi Arabia \\ ${ }^{3}$ Faculty of Science, Community College, King Abdulaziz University, Jeddah, Saudi Arabia \\ ${ }^{4}$ Medical Services Department, Security Forces Polyclinics, Jeddah, Saudi Arabia \\ ${ }^{5}$ Department of Computer Science, King Abdulaziz University, Jeddah, Saudi Arabia \\ Email: anabdrabo@uqu.edu.sa,whmalki@uqu.edu.sa,mhmukhtar@uqu.edu.sa, isazmi001@hotmail.com, \\ "iyshahid@uqu.edu.sa, captenmd2001@yahoo.com, totatotarya@yahoo.com
}

Received 25 May 2016; accepted 27 August 2016; published 30 August 2016

Copyright (C) 2016 by authors and Scientific Research Publishing Inc.

This work is licensed under the Creative Commons Attribution International License (CC BY). http://creativecommons.org/licenses/by/4.0/

(c) (i) Open Access

\section{Abstract}

Doxorubicin is a commonly used anticancer agent, which may cause cardiac toxicity. The present study designed to evaluate Phoenix dactylofera (dates) in doxorubicin (DXR) induced cardiac toxicity and cardiac remodeling in Wistar albino rats. The experimental rats procured, acclimatized and finally divided into five groups $(n=6)$. Group I served as normal controls, group II served as disease controls and groups $3,4 \& 5$ served as therapeutic groups (Phoenix dactylofera $5 \%, 10 \%$, and $15 \%$ respectively). Cardiac remodeling and toxicity in the rats were induced by administration of DXR (1.25 mg/kg i.p. in 16 divided doses/month). At the end of protocol, effect of Phoenix dactylofera on cardiac remodeling was evaluated by measuring parameters like haemodynamics, heart weight, anatomy, Troponin T, creatine phosphokinase (CPK), creatine phosphokinase-MB (CPK-MB), Lactate dehydrogenase (LDH), serum glutamate oxaloacetate transaminase (SGOT), serum glutamate pyruvate transaminase (SGPT), calcium ion $\mathrm{Ca}^{2+}$, sodium ion $\mathrm{Na}^{+}$, potassium ion $\mathrm{K}^{+}$, intracellular enzymes like Malondialdehyde (MDA), glutathione (GSH), superoxide dismutase (SOD) and catalase (CAT). The disease control groups showed significantly elevated $(p<0.001)$ levels of troponin T, CPK, CPK-MB, LDH, MDA, and significantly reduced levels $(p<0.001)$ of GSH, SOD \& CAT while the levels of SGPT, SGOT were increased less significantly $(p<0.01)$ as compared to therapeutic groups. Treatment with Phoenix dactylofera significantly $(\mathrm{p}<0.01)$ reduced the increased levels of Troponin T, CPK, CPK-MB, LDH, SGOT, SGPT, MDA, GSH, SOD \& CAT as well as restored $\mathrm{Ca}^{2+}, \mathrm{Na}^{+}, \mathrm{K}^{+}$levels to a normal value. Further, the histological studies of the cardiac tissues demonstrated that the normal architecture of the cardiac cells was restored in the animals fed

\footnotetext{
${ }^{*}$ Corresponding author.
}

How to cite this paper: Abdalla, A.N., Almaliki, W.H., Mukhtar, M.H., Anwar, F., Shahid, I., Menshawi, S.A. and Alsulimani, T.S. (2016) Ameliorative Influence of Dietary Dates on Doxorubicin-Induced Cardiac Toxicity. Pharmacology \& Pharmacy, 7, 343-353. http://dx.doi.org/10.4236/pp.2016.78042 
with dietary Phoenix dactylofera as compared to disease controls. The findings show that the administration of Phoenix dactylofera has the potential to prevent the toxicity induced by doxorubicin in the experimental rats.

\title{
Keywords
}

\author{
Cardiac Remodeling, Phoenix dactylofera, Biochemical Parameters, Protection, Doxorubicin
}

\section{Introduction}

Cardiac dysfunction is defined as an alteration in the relationship between preload (often defined by left ventricular filling pressure) and stroke volume. This relationship is depicted by Frank-Starling curves, which identify a shift downward and to the right as cardiac dysfunction [1]. Remodeling is defined as an alteration in the structure (dimensions, mass, shape) of the heart (called cardiac or ventricular remodeling) in response to hemodynamic load and/or cardiac injury in association with neurohormonal activation. Remodeling may be described as physiologic or pathologic [2]. The remodeling process frequently includes increases in myocardial mass. The heart can respond to environmental stimuli by growth (increased myocardial mass) or shrinkage (atrophy) with a dynamic range of at least 100 percent [3]. Myocardial hypertrophy is most properly defined as increased cardiomyocyte size which may occur with or without an increase in overall myocardial mass; however, the term "hypertrophy" has also been used to denote increased myocardial mass and/or wall thickness. Physiologic remodeling is a compensatory change in the dimensions and function of the heart in response to physiologic stimuli such as exercise and pregnancy. This type of remodeling is seen in athletes and has been called athlete's heart [3]. Pathologic remodeling may occur with pressure overload (e.g., aortic stenosis, hypertension), volume overload (e.g., valvular regurgitation), or following cardiac injury (e.g., myocardial infarction, myocarditis, or idiopathic dilated cardiomyopathy). In each of these settings, remodeling may transition from an apparently compensatory process to a maladaptive one [3].

Phoenix dactylifera L. commonly known as the date palm is an important plant in the scorched regions of Southwest Asia and North Africa. The fruits which are the most commonly used part are a primary source of nutrition, especially in the arid areas where due to the extreme conditions, very few plants can grow [4]. Date fruit consists of $70 \%$ carbohydrates, most of which is in the form of sugars. Because of this, the fruits are a high source of energy and it is approximated that $100 \mathrm{~g}$ of the flesh can provide $314 \mathrm{kcal}$ of energy [4]. Drying of date decreases the water activity, and this increases the sugar concentration. Because of this, the shelf life of dry dates are high and are available for extended periods of time [5]. The fruits are also used as a sweetener in the preparation of beer [5]. In Saudi Arabia, it is most widely used dietary food. Phytochemical investigations have revealed that the fruits contain anthocyanins, phenolics, sterols, carotenoids, procyanidins and flavonoids, compounds known to possess multiple beneficial effects. Preclinical studies have shown that the date fruits possess free radical scavenging, antioxidant, antimutagenic, antimicrobial, anti-inflammatory, gastroprotective, hepatoprotective, nephroprotective, anticancer and immunostimulant activities [6] [7]. Problems associated with the cardiovascular system are prevalent in Saudi Arabia and still need exploration to overcome these challenges [8] [9].

Doxorubicin an anthracycline antibiotic has been widely used for the treatment of a variety of cancers such as breast cancers, carcinoma of small cells of lungs and leukemias [10]. However, the use of doxorubicin is limited because of its acute and chronic toxicities. The acute toxicities are myelosuppression, nausea, vomiting and arrhythmias are reversible while the chronic toxicities such as cardiomyopathy and heart failure are irreversible and unmanageable [11]. The exact mechanism is still not known but the possible mechanisms have been postulated by the various researchers such as generation of oxidative stress [12], induction of apoptosis [13], activation of renin-angiotensin system (RAAS) [14], oxidative stress induced DNA damage [15], lipid peroxidation and impairment of enzyme activity of creatinine kinase [16] [17]. Several drugs have been evaluated for the treatment of doxorubicin-induced cardiomyopathy by various researchers. Therefore by reviewing above and many more literature in doxorubicin-induced cardiomyopathy and cardiac failure and the use of dietary supplement Phoenix 
dactylofera in the treatment of various disease and for the inhibition of different disease inducing endogenous substances, here the present study designed to evaluate the ameliorative potential of the Phoenix dactylofera in doxorubicin-induced cardiomyopathy and cardiac failure.

\section{Material and Methods}

\subsection{Experimental Animals}

Laboratory-bred Wistar albino rats weighing 150 - 200 g at age 6 - 8 weeks of either sex were procured and housed six per cage under standard laboratory conditions at a room temperature $22^{\circ} \mathrm{C} \pm 2{ }^{\circ} \mathrm{C}$ with $12 \mathrm{~h} \mathrm{light/dark}$ cycle. The animals were purchased from the animal facility of the pharmacology department, Siddartha Institute of Pharmacy, Dehradun. The animals provided with normal pellet diet water ad libitum and acclimatized for one week. All experiments conducted between 09:00 and 17:00 h. The experimental protocol was approved by Institutional Animal Ethics Committee of Siddhartha Institute of Pharmacy, Dehradun and all the experimental procedure used were as per guidelines of Committee for the Purpose of Control and Supervision of Experimental Animals (CPCSEA), New Delhi.

\subsection{Drugs and Chemicals}

Doxorubicin was purchased from MAX health care Dehradun, India. Phoenix dactylofera was purchased from the local market of Makkah, Saudi Arabia. All the other drugs and chemicals utilized were of analytical grade.

\subsection{Experimental Design}

After acclimatization, the animals were divided randomly into five groups $(n=6)$ and treatment schedule was as follows: Group1 rats served as normal controls and fed with normal diet during the whole study, group 2 rats served as disease controls administered with Doxorubicin $1.25 \mathrm{mg} / \mathrm{kg}$ i.p. in 16 divided doses/month. Group 3, 4 and 5 rats served as therapeutic groups which were administered with Doxorubicin $1.25 \mathrm{mg} / \mathrm{kg}$ IP in 16 divided doses/month and treated with Phoenix dactylofera (5\%,10\% and 15\% in diet respectively for one month).

After $24 \mathrm{~h}$ of the last dose of Doxorubicin, blood samples were collected from retro-orbital plexuses under light ether anesthesia from all experimental rats under study. The enzymatic parameters (LDH, SGPT, SGOT, $\mathrm{Na}^{+}, \mathrm{Ca}^{2+}$ and $\mathrm{K}^{+}$) were estimated in blood. Troponin-T, CPK, CK-MB, were estimated using test strips. Heart excised, washed in ice-cold physiological saline, a small portion of heart was weighed and homogenized for biochemical estimations (malondialdehyde [MDA], glutathione [GSH], superoxide dismutase [SOD] and catalase [CAT]). Remaining part of the heart preserved in phosphate buffer (strength $100 \mathrm{mM}$, PH 7.4) for histological studies.

\subsection{Hemodynamic Measurements}

Hemodynamic measurements were done by tail cuff method on Biopac Non-Invasive Blood Pressure Recording Instrument (USA). All the rats trained in the restrainer initially for 15 min every day at least 10 - 15 days before the day of measurement of the hemodynamic parameters (systolic, diastolic, mean blood pressure and heart rate) and then the final measurement were done.

\subsection{Biochemical Estimation in Serum}

Creatine phosphokinase, Troponin-T, Creatine kinase myocardial band isoenzyme (CK-MB) were estimated using the test strips, while LDH, SGPT, SGOT, $\mathrm{Na}^{+}, \mathrm{Ca}^{2+}$ and $\mathrm{K}^{+}$were estimated in serum by enzymatic kits using biochemistry semi auto analyzer, Nicholas Piramal 5010.

\subsection{Biochemical Assay in Cardiac Tissues Homogenates}

Measurement of lipid peroxidation was done as per the method of Ohkawa [18]. Antioxidant enzymes GSH, SOD, and CAT, were determined in cardiac tissue as per standard protocol. GSH estimated by Ellman method, Activity of SOD measured by the method of Marklund, CAT activity was measured according to the method of Clairbone [19]. 


\subsection{Histology}

Samples fixed in modified Karnovasky's solution and buffered in $0.1 \mathrm{M}$ sodium phosphate buffer (pH 7.4). Fixation was done for 8 to $12 \mathrm{~h}$ at $4^{\circ} \mathrm{C}$ then the tissues washed with $0.1 \mathrm{M}$ sodium phosphate buffer. After several washings specimens desiccated in graded acetone solutions and rooted in CY212 Araldite. Thin sections of 60 to $80 \mathrm{~nm}$ thickness were incised using microtome, and the sections were stained with alcoholic uranyl acetate (10 $\mathrm{min})$ and lead citrate (10 min) then the histological studies performed.

\subsection{Statistical Analysis}

Results were expressed as mean \pm standard error of mean (S.E.M.). Groups of data were compared with the analysis of variance (ANOVA) followed by Dunnett's t-test. Values were considered statistically significant at P $<0.05,0.01$ and 0.001 respectively.

\section{Results}

\subsection{Hemodynamic Parameters}

The systolic, diastolic, mean blood pressure and heart rate were found significantly $(\mathrm{P}<0.01)$ increased in disease control group (group 2) as compared to the normal control group (group I) while treatment of Phoenix dactylofera (5\%, $10 \%$ and $15 \%$ respectively) in diet (group 3, 4 and 5) caused significant $(\mathrm{P}<0.05 ; \mathrm{P}<0.01 ; \mathrm{P}<0.001$ ) reduction in group 3 and 4 . The dietary treatment with Phoenix dactylofera (10\% completely restored the systolic, diastolic, mean blood pressure and heart rate as compared to the doxorubicin control group (Table 1, Figure 1).

\subsection{Creatine Kinase, Troponin T, Creatine Kinase Myocardial Band Isoenzyme (CK-MB) and Lactate Dehydrogenase (LDH) Activities}

Treatment of rats with DXR (1.6 mg/kg in 16 divided doses/month, i.p.) caused a significant $(\mathrm{P}<0.01$; $\mathrm{P}<$ 0.001) increase in both serum CK, troponin T, CK-MB and LDH enzyme activities as compared to their respective values in normal controls. Dietary intake of Phoenix dactylofera $(10 \%)$ significantly $(\mathrm{P}<0.01)$ reduced their elevated levels and restored them almost to normal (Table 2, Figure 2(a) \& Figure 2(b)).

\subsection{Serum SGOT, SGPT, $\mathrm{Na}^{+}, \mathrm{Ca}^{2+}$ and $\mathrm{K}^{+}$}

The significant elevations ( $\mathrm{P}<0.01 ; \mathrm{P}<0.001)$ found in serum SGOT, SGPT levels of the disease controls as compared to normal controls. Dietary intake of Phoenix dactylofera caused the significant $(\mathrm{P}<0.01)$ reduction. The significant results were observed in the animals fed with Phoenix dactylofera (10\%). There were no significant alterations found in the levels of serum $\mathrm{Na}^{+}, \mathrm{Ca}^{2+}$ and $\mathrm{K}^{+}$in both normal controls, disease controls and therapeutic controls (Table 3, Figure 3).

\subsection{Lipid Peroxidation (Malondialdehyde [MDA])}

Lipid peroxide levels were determined by evaluating myocardial MDA content. MDA levels were significantly $(\mathrm{P}<0.01 ; \mathrm{P}<0.001$ ) higher in the doxorubicin control group (Group 2) as compared to normal controls (Group 1).

\begin{tabular}{ccccc}
\hline \multicolumn{4}{l}{ Table 1. Effect of dates on different hemodynamic parameters. } \\
\hline Experimental Groups & Systolic BP (mm Hg) & Diastolic BP (mm Hg) & Mean BP (mm Hg) & Heart rate (beats/min) \\
\hline Normal Control & $135.3 \pm 1.36$ & $91.55 \pm 0.98$ & $115.44 \pm 0.79$ & $376.44 \pm 3.90$ \\
Doxorubicin Control & $196.3 \pm 2.47^{\mathrm{B}}$ & $121.57 \pm 1.40^{\mathrm{B}}$ & $179.22 \pm 1.30^{\mathrm{B}}$ & $521.11 \pm 3.08^{\mathrm{B}}$ \\
Dates Control (5\%) & $174.1 \pm 2.40^{\mathrm{b}}$ & $105.98 \pm 1.36^{\mathrm{b}}$ & $154.10 \pm 0.77^{\mathrm{C}}$ & $412.10 \pm 3.82^{\mathrm{b}}$ \\
Dates Control (10\%) & $149.7 \pm 1.81^{\mathrm{b}}$ & $99.99 \pm 1.05^{\mathrm{C}}$ & $124.02 \pm 0.90^{\mathrm{b}}$ & $387.20 \pm 3.78^{\mathrm{a}}$ \\
Dates Control (15\%) & $155.8 \pm 2.01^{\mathrm{C}}$ & $101.04 \pm 1.03^{\mathrm{C}}$ & $125.91 \pm 0.50^{\mathrm{b}}$ & $438.29 \pm 3.30^{\mathrm{b}}$ \\
\hline
\end{tabular}

${ }^{\mathrm{a}}=\mathrm{P}<0.05,{ }^{\mathrm{b}}=\mathrm{P}<0.01$, and ${ }^{\mathrm{c}}=\mathrm{P}<0.001$ compared to doxorubicin control; whereas ${ }^{\mathrm{B}}=\mathrm{P}<0.01$ as compared to normal control. $\mathrm{a}=*$, $\mathrm{b}=\mathrm{q}$, $\mathrm{C}=+$, $\mathrm{B}=\#$ (as shown in Figure 1). 


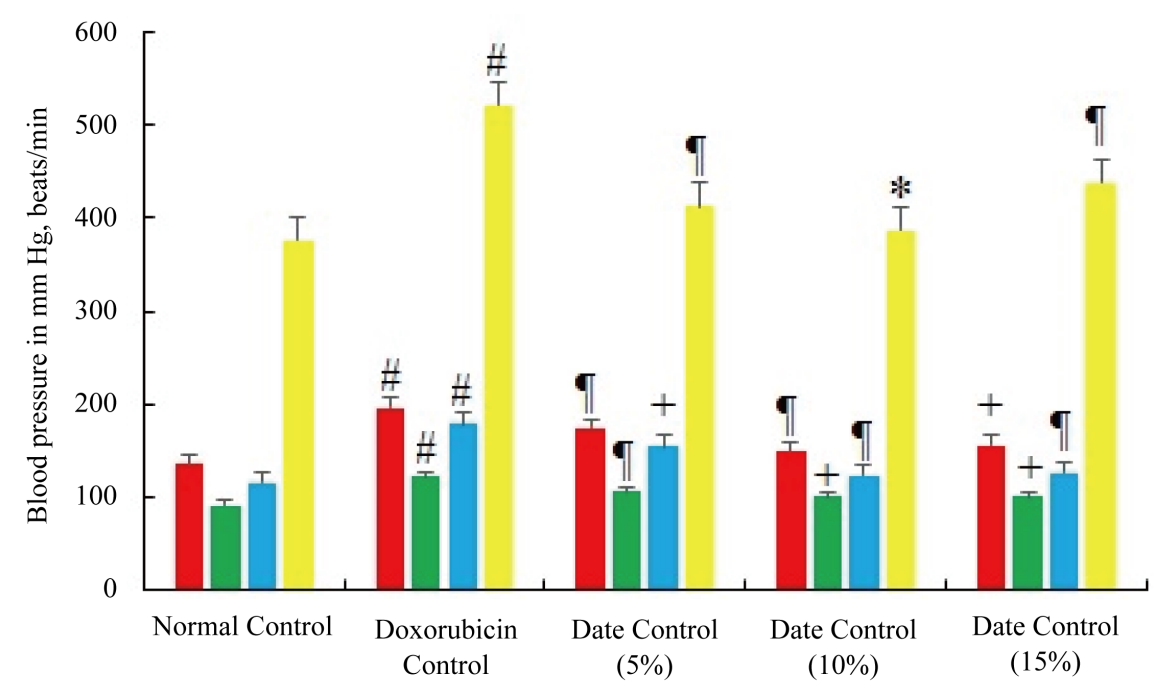

Experimental design

घystolic BP Diastolic BP $\quad$ Mean BP Heart rate

\begin{abstract}
Figure 1. The effect of Phoenix dactylofera on blood pressure and heart rate in mice: Each trial was performed in triplicate. The data were expressed as Mean \pm S.E.M. Where $n=6$ in each group. P-value $<0.05$, 0.01 , and 0.001 were considered statistically significant as compared to Doxorubicin control; whereas P-value $<0.01$ as compared to Normal Control (one-way ANOVA followed by Tukey's post-test). BP = Blood pressure. For systolic, diastolic and mean BP, the measuring units were expressed in $\mathrm{mm} \mathrm{Hg}$ on $\mathrm{Y}$-axis, while the heart beat was measureed in beats/minute. $\mathrm{P}<0.05=*, \mathrm{P}<0.01=$ I, $\mathrm{P}<0.001=+, \mathrm{P}<$ $0.01=\#$.
\end{abstract}

Table 2. Effect of dates on different biochemical parameters.

\begin{tabular}{|c|c|c|c|c|}
\hline Experimental Groups & Troponin T (U/L) & CPK (U/L) & CPK-MB (U/L) & LDH (U/L) \\
\hline Normal Control & $0.31 \pm 0.01$ & $155.48 \pm 2.67$ & $88.49 \pm 0.89$ & $83.40 \pm 0.81$ \\
\hline Doxorubicin Control & $2.32 \pm 0.11^{\mathrm{B}}$ & $475.49 \pm 3.30^{\mathrm{C}}$ & $199.01 \pm 1.87^{\mathrm{B}}$ & $319.10 \pm 3.09$ \\
\hline Dates Control (5\%) & $0.42 \pm 0.03^{b}$ & $181.22 \pm 1.31^{\mathrm{b}}$ & $95.32 \pm 1.03^{b}$ & $93.20 \pm 0.88$ \\
\hline Dates Control (10\%) & $0.37 \pm 0.01^{\mathrm{b}}$ & $164.79 \pm 1.05^{\mathrm{b}}$ & $85.02 \pm 0.66^{b}$ & $89.01 \pm 0.88$ \\
\hline Dates Control (15\%) & $0.36 \pm 0.02^{\mathrm{c}}$ & $165.55 \pm 1.06^{\mathrm{b}}$ & $86.30 \pm 0.45^{\mathrm{b}}$ & $91.31 \pm 1.02^{\mathrm{b}}$ \\
\hline
\end{tabular}

${ }^{\mathrm{a}}=\mathrm{P}<0.05,^{\mathrm{b}}=\mathrm{P}<0.01$, and $^{\mathrm{C}}=\mathrm{P}<0.001$ compared to doxorubicin control; whereas ${ }^{\mathrm{B}}=\mathrm{P}<0.01$, and ${ }^{\mathrm{C}}=\mathrm{P}<0.001$ as compared to normal control. Where $\mathrm{a}=*, \mathrm{~b}=\boldsymbol{q}, \mathrm{c}=+, \mathrm{B}=\#, \mathrm{C}=\times$ as shown in Figure 2(a), Figure 2(b).

Table 3. Effect of dates on serum SGOT, SGPT, Calcium, sodium and potassium of animals.

\begin{tabular}{cccccc}
\hline Experimental Groups & SGPT $(\mathrm{mg} / \mathrm{dl})$ & SGOT $(\mathrm{mg} / \mathrm{dl})$ & $\mathrm{Ca}^{2+}(\mathrm{mg} \%)$ & $\mathrm{Na}^{+}(\mathrm{m} . \mathrm{eq} / \mathrm{L})$ & $\mathrm{K}^{+}(\mathrm{m} . \mathrm{eq} / \mathrm{L})$ \\
\hline Normal Control & $49.99 \pm 046$ & $55.23 \pm 1.04$ & $9.01 \pm 0.03$ & $6.66 \pm 0.15$ & $9.88 \pm 0.14$ \\
Doxorubicin Control & $79.29 \pm 0.59^{\mathrm{B}}$ & $80.10 \pm 0.92^{\mathrm{C}}$ & $14.09 \pm 0.11^{\mathrm{B}}$ & $7.9 \pm 0.18^{\mathrm{B}}$ & $6.67 \pm 0.13$ \\
Dates Control (5\%) & $66.10 \pm 0.69^{\mathrm{a}}$ & $48.33 \pm 0.77^{\mathrm{a}}$ & $10.12 \pm 0.12^{\mathrm{b}}$ & $6.51 \pm 0.10^{\mathrm{b}}$ & $8.89 \pm 0.18$ \\
Dates Control (10\%) & $44.40 \pm 0.13^{\mathrm{b}}$ & $54.23 \pm 0.66^{\mathrm{b}}$ & $9.55 \pm 0.09^{\mathrm{b}}$ & $6.59 \pm 0.12^{\mathrm{b}}$ & $9.02 \pm 0.21$ \\
Dates Control (15\%) & $50.11 \pm 0.50^{\mathrm{b}}$ & $40.29 \pm 0.22^{\mathrm{C}}$ & $10.41 \pm 0.07^{\mathrm{b}}$ & $5.98 \pm 0.15^{\mathrm{b}}$ & $8.81 \pm 0.32^{\mathrm{b}}$ \\
\hline
\end{tabular}

${ }^{\mathrm{a}}=\mathrm{P}<0.05,^{\mathrm{b}}=\mathrm{P}<0.01$ and $^{\mathrm{C}}=\mathrm{P}<0.001$ compared to doxorubicin control; whereas $^{\mathrm{B}}=\mathrm{P}<0.01$ and $^{\mathrm{C}}=\mathrm{P}<0.001$ as compared to normal control and $\mathrm{a}=*, \mathrm{~b}=\boldsymbol{\uparrow}, \mathrm{c}=+, \mathrm{B}=\#, \mathrm{C}=\mathrm{x}$ as shown in Figure 3 . 

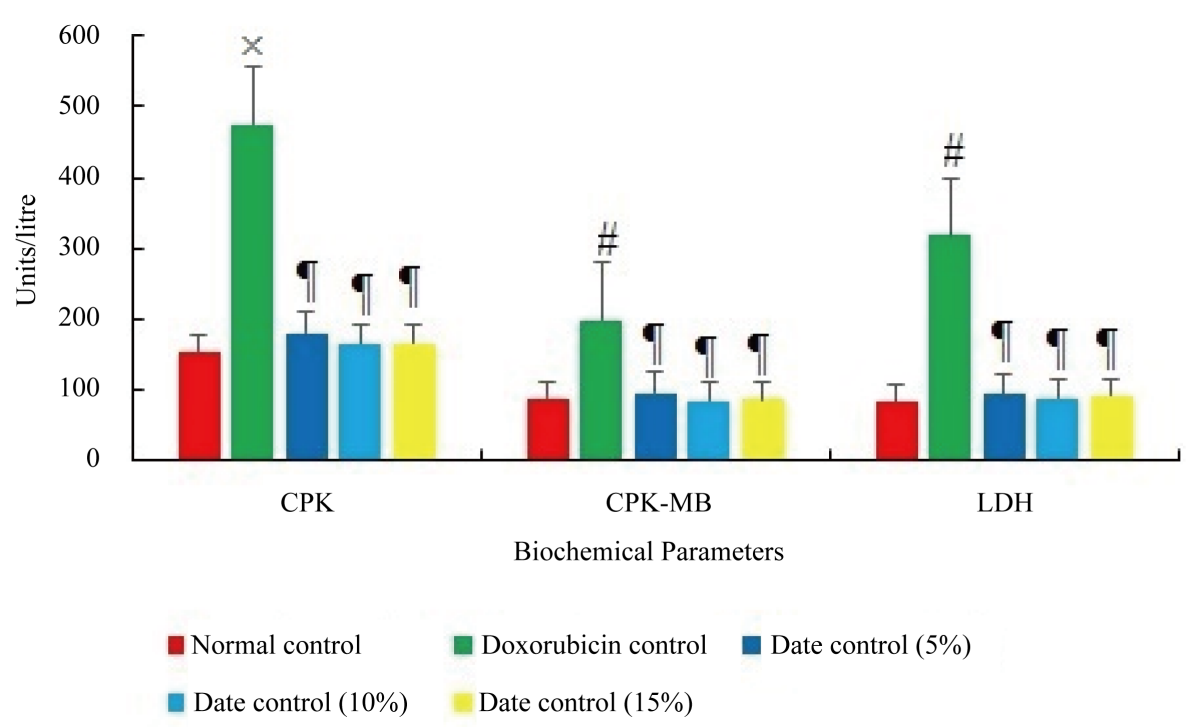

(a)

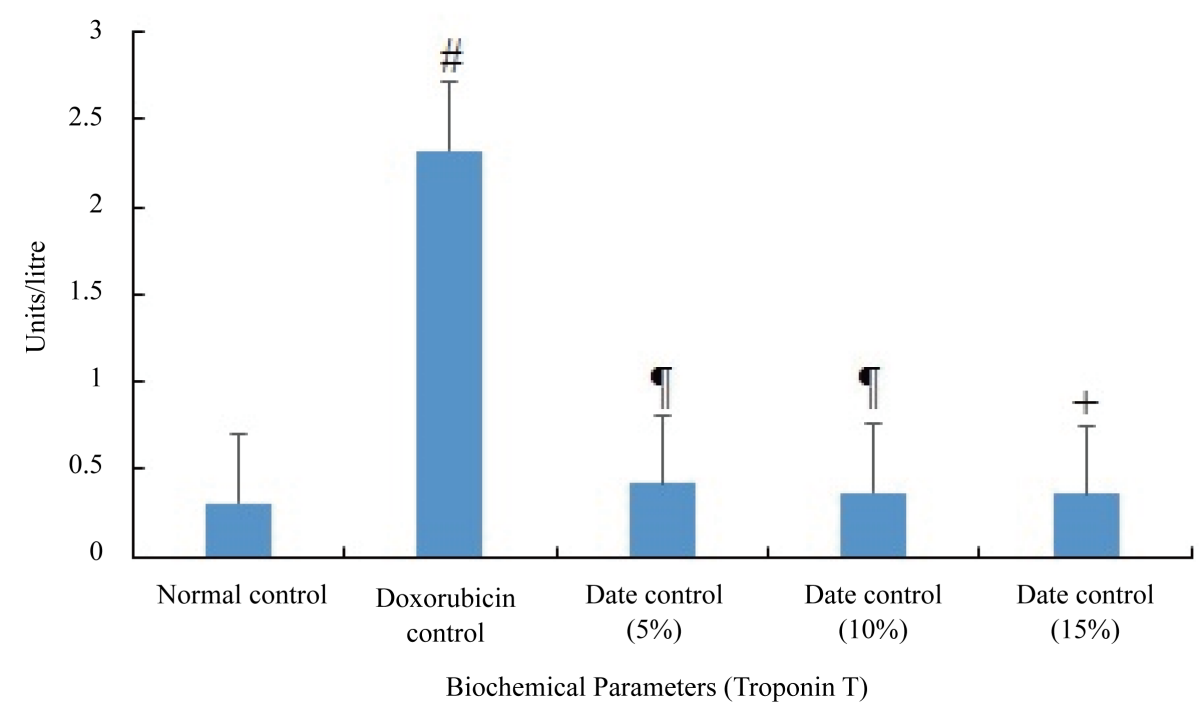

(b)

Figure 2. (a) The CPK, CPK-MB and LDH levels in mice treated with Phoenix dactylofera: Each trial was performed in triplicate. The data were presented as Mean \pm S.E.M. Where $n=6$ in each group. P-value < 0.05, 0.01, and 0.001 were considered statistically significant as compared to Doxorubicin control; whereas P-value $<0.01$ as compared to Normal Control (one-way ANOVA followed by Tukey's post-test). CPK = Creatine phosphokinase, CPK-MB = Creatine phosphokinase myocardial band, $\mathrm{LDH}=$ Lectate dehydrogenase. $\mathrm{P}<0.05=*, \mathrm{P}<0.01=\mathbb{I}, \mathrm{P}<0.001=+, \mathrm{P}<0.01=\#, \mathrm{P}<0.001=\times$. (b) Troponin $\mathrm{T}$ level in mice treated with Phoenix dactylofera: Each trial was performed in triplicate. The data were presented as Mean \pm S.E.M. Where $n=6$ in each group. P-value $<0.05,0.01$, and 0.001 were considered statistically significant as compared to Doxorubicin control; whereas P-value $<0.01$ as compared to Normal Control (one-way ANOVA followed by Tukey's post-test). $\mathrm{P}<0.01=$ II, $\mathrm{P}<0.001=+, \mathrm{P}<0.01=\#$.

MDA levels were found significantly ( $\mathrm{P}<0.05$; $\mathrm{P}<0.01$; $\mathrm{P}<0.001$ ) decreased in the Phoenix dactylofera $(5 \%$, $10 \%$ and 15\%) treated groups (group 3 and 4 and 5 ) as well as the MDA level was also found decreased significantly ( $\mathrm{P}<0.05 ; \mathrm{P}<0.01)$ in Phoenix dactylofera (10\%) fed group (Table 4, Figure 4).

\subsection{Antioxidant Enzymes}

The Doxorubicin control group showed significantly increased CAT while GSH and SOD were significantly 

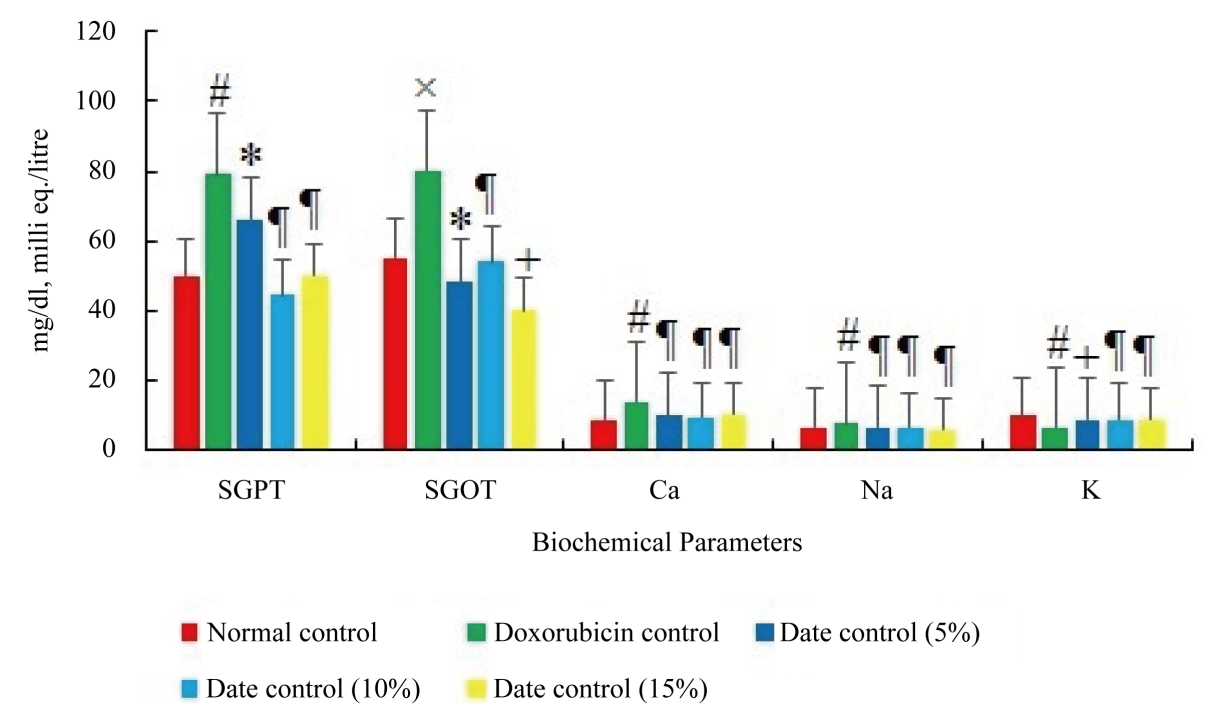

Figure 3. The serum SGPT, SGOT and serum electrolyte values in mice treated with Phoenix dactylofera: Each trial was performed in triplicate. The data were presented as Mean \pm S.E.M. Where $n=6$ in each group. P-value $<0.05,0.01$, and 0.001 were considered statistically significant as compared to Doxorubicin control; whereas P-value $<0.01$ and $<0.001$ as compared to Normal Control (one-way ANOVA followed by Tukey's post-test). SGPT = serum glutamate pyruvate transaminase, SGOT = serum glutamate oxaloacetate transaminase. The serum SGPT, SGOT were measured in mg/dl, serum $\mathrm{Ca}^{2+}$ was determined in $\mathrm{mg} \%$, while $\mathrm{Na}^{+}$and $\mathrm{K}^{+}$were determined in milli eq./litre. $\mathrm{P}<0.05=*, \mathrm{P}<0.01=\mathbf{q}, \mathrm{P}<0.001=+$, $\mathrm{P}<0.01=\#, \mathrm{P}<0.001=\times$.

Table 4. Effect of dates on antioxidant enzyme levels in rats.

\begin{tabular}{ccccc}
\hline Experimental Groups & MDA ((nM/mg protein) & $\begin{array}{c}\mathrm{GPx}(\mu \mathrm{M} \text { of GSH} / \mathrm{min} / \mathrm{mg} \\
\text { protein })\end{array}$ & $\begin{array}{c}\mathrm{CAT}(\mu \mathrm{M} \text { of } \\
\left.\mathrm{H}_{2} \mathrm{O}_{2} / \mathrm{min} / \mathrm{mg} \text { protein }\right)\end{array}$ & SOD (U/mg protein) \\
\hline Normal Control & $3.17 \pm 0.22$ & $26.22 \pm 0.57$ & $134.30 \pm 1.14$ & $8.19 \pm 0.08$ \\
Doxorubicin Control & $1.66 \pm 0.11^{\mathrm{B}}$ & $10.50 \pm 0.08^{\mathrm{B}}$ & $79.36 \pm 0.59^{\mathrm{C}}$ & $4.55 \pm 0.33^{\mathrm{C}}$ \\
Dates Control (5\%) & $3.34 \pm 0.19^{\mathrm{a}}$ & $19.11 \pm 0.10^{\mathrm{c}}$ & $99.05 \pm 0.71^{\mathrm{c}}$ & $5.20 \pm 0.28^{\mathrm{b}}$ \\
Dates Control (10\%) & $3.01 \pm 0.40^{\mathrm{b}}$ & $20.89 \pm 0.32^{\mathrm{a}}$ & $126.50 \pm 0.33^{\mathrm{b}}$ & $7.99 \pm 0.49^{\mathrm{a}}$ \\
Dates Control (15\%) & $2.79 \pm 0.41^{\mathrm{c}}$ & $21.87 \pm 0.87^{\mathrm{b}}$ & $117.49 \pm 0.81^{\mathrm{a}}$ & $7.01 \pm 0.19^{\mathrm{c}}$ \\
\hline
\end{tabular}

${ }^{\mathrm{a}}=\mathrm{P}<0.05,^{\mathrm{b}}=\mathrm{P}<0.01$, and $^{\mathrm{C}}=\mathrm{P}<0.001$ compared to doxorubicin control; whereas $^{\mathrm{B}}=\mathrm{P}<0.01$, and $^{\mathrm{C}}=\mathrm{P}<0.001$ as compared to normal control and $\mathrm{a}=*, \mathrm{~b}=\boldsymbol{\uparrow}, \mathrm{c}=+, \mathrm{B}=\#, \mathrm{C}=\times$ as shown in Figure 4.

decreased as compared to normal controls. Treatment with Phoenix dactylofera $10 \%$ in the diet significantly restored the levels of antioxidant enzymes towards normal value as compared to other therapeutic groups too. (Table 4, Figure 4).

\subsection{Histopathological Examinations}

Histopathological photographs of normal control myocardial cells showed normal nucleus, myofibril, and mitochondria (Figure 5(a)). In doxorubicin-treated disease control group showed vacuolation of the endoplasmic reticulum, swelling of mitochondria with disrupt cristae, broken nuclear membrane, condensation and margination of nuclear chromatin at the nuclear membrane and nucleus (Figure 5(b)). Dates treated group showed homogeneous chromatin and normal structure of the nucleus and nuclear membrane (Figures 5(c)-(e)).

\section{Discussion}

Doxorubicin (DXR) is one of the most important chemotherapeutic substitutes for solid tumors such as carcinomas of breast and lung, and soft tissue sarcomas [10]. Due to severe toxic effects and development of cardiomyopathy and cardiac failure the use of DXR is limited [11]. Although the mechanism for the development of 


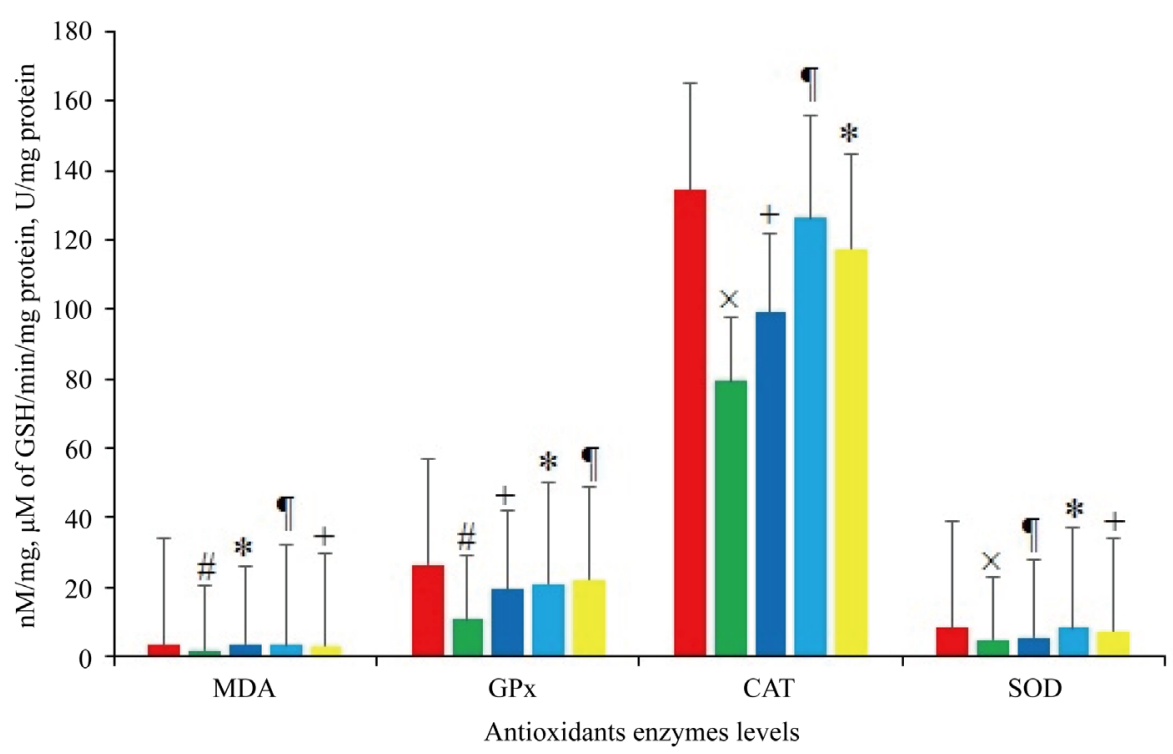

a Normal control $\square$ Doxorubicin control $\square$ Date control (5\%) $\square$ Date control (10\%) Date control (15\%)

Figure 4. The antioxidant enzyme levels in mice treated with Phoenix dactylofera: Each trial was performed in triplicate. The data were presented as Mean \pm S.E.M. Where $n=6$ in each group. P-value $<0.05,0.01$, and 0.001 were considered statistically significant as compared to Doxorubicin control; whereas P-value $<0.01$ and $<0.001$ as compared to Normal Control (one-way ANOVA followed by Tukey's post-test). MDA = Malondialdehyde, GPx = Glutathione Peroxidase, CAT = Catalase, SOD = Superoxide dismutase, The MDA concentration was measured in nanoMole/mg of protein, GPx was determined in $\mu \mathrm{M}$ of GSH/min/mg protein, CAT was measured in $\mu \mathrm{M}$ of $\mathrm{H}_{2} \mathrm{O}_{2} / \mathrm{min} / \mathrm{mg}$ protein, and SOD was measured in $\mathrm{U} / \mathrm{mg}$ of protein. $\mathrm{P}<0.05=*, \mathrm{P}<0.01=$ I, $\mathrm{P}<0.001=$ $+, \mathrm{P}<0.01=\#, \mathrm{P}<0.001=\times$.

cardiomyopathy is not well understood still DXR is well-established drug for the induction of cardiac toxicity which ultimately lead to cardiac remodeling by various mechanism such as ROS generation [20], Increasing $\mathrm{Ca}^{2+}$ overload in the cardiocytes [21], metabolite accumulation [22], stimulating the production of prostaglandins [23] and thromboxanes, stimulating histamine release [24], indirect interaction with the actin-myosin contractile system in the heart by both positive ionotropic [25] and negative ionotropic effects [26]. Here in the present research protocol, it has been confirmed again that DXR in 16 equal cumulative doses $(1.25 \mathrm{mg} / \mathrm{kg}$ i.p.) has the capability to induce chronic cardiomyopathy in rats which substantiate the findings of the previous researchers.

Earlier the researchers worked and stated that the administration of DXR causes an alteration in the systolic, diastolic and mean blood pressure, as well as heart rate [27]. The present research study also demonstrated the significant increase $(\mathrm{P}<0.01)$ of systolic, diastolic, mean blood pressure and heart rate in the disease control rats as compared to normal controls (Table 1, Figure 1). Moreover, the decrease in body \& heart weights certifies the claims of the previous investigators [28]. These findings may be due to the deleterious effects on intestinal mucus membrane which had led to decreasing food intake and reduced secretions of intestinal hormones [29]. Results of the present research demonstrate that administration of Phoenix dactylofera restored the hemodynamics (systolic, diastolic and mean blood pressure and heart rate) towards normal value (Table 1). Furthermore, the body and heart weight were also found maintained towards normal value in the animals fed with Phoenix dactylofera.

Further serum levels of troponin T, CK, CK-MB and LDH are important myocardial enzymes for the evaluation of cardiotoxicity and congestive heart failure [30]. A number of scientists found the elevation of serum troponin T, CK, CK-MB and LDH during the cardiotoxic events. In the present research protocol, serum levels of these enzymes were also found significantly increased in the disease control group, whereas dietary intake of Phoenix dactylofera prevented this increase markedly, indicating cardioprotective efficacy against DXR toxicity (Table 2, Figure 2(a) \& Figure 2(b)).

Scientists have observed and proved already the involvement of ROS in the generation of myocardial injury and congestive cardiac failure [31]. Our findings demonstrate that The DXR exposure lead to the significant increment in ROS generation in cardiomyocytes and exhibited a significant $(\mathrm{P}<0.01)$ rise in the MDA and CAT 


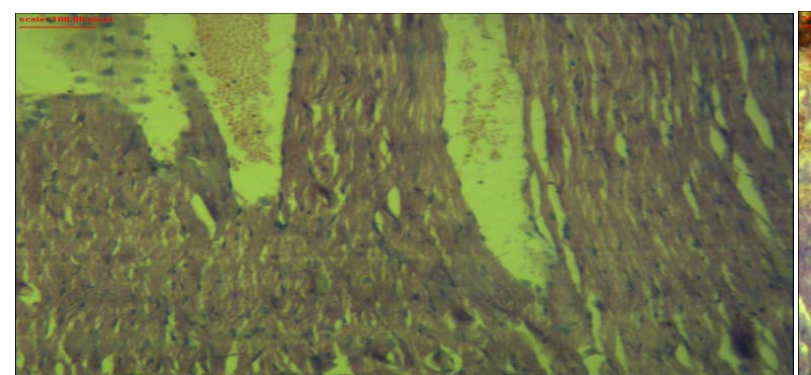

(a)

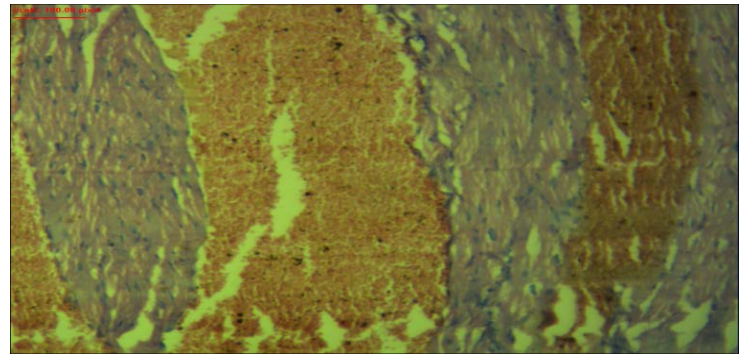

(c)

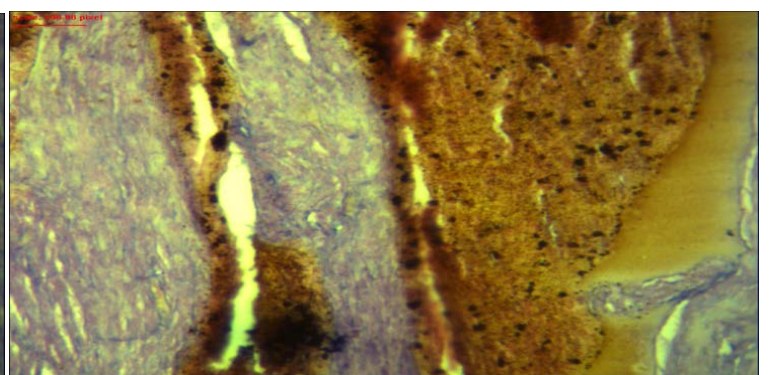

(b)

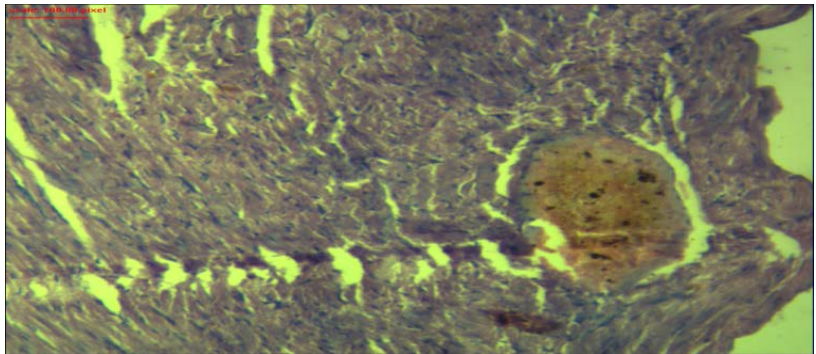

(d)

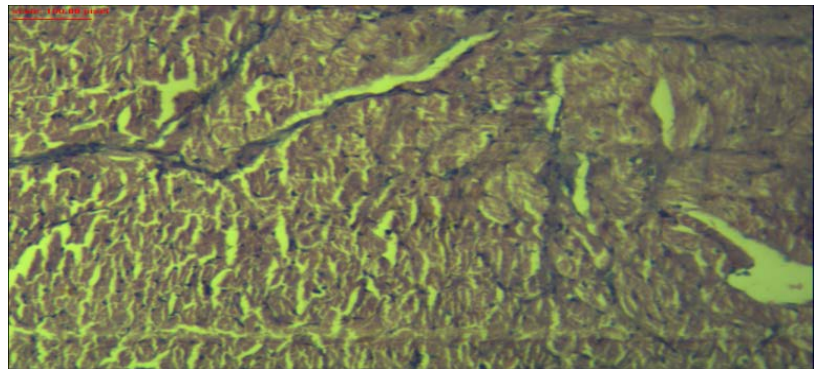

(e)

Figure 5. Histopathological studies showing morphological changes in rat cardiomyocytes: (a) In normal control, rat cardiomyocytes shows regular nucleus and intact myofibril and mitochondria; (b) In doxorubicin (1.25 mg/kg in 16 divided doses/month) treated rats, cardiomyocytes showed vacuolation of the endoplasmic reticulum, swelling of mitochondria with disrupt cristae, broken nuclear membrane, condensation and margination of nuclear chromatin at the nuclear membrane and nucleus; (c)-(e) Phoenix dactylofera (5\% - 15\% in diet) treated rats showed an altered architecture of the cardiomyocytes with homogeneous chromatin and normal structure of the nucleus and nuclear membrane indicating restoration of normal cardiomyocytes morphology and physiology.

concentration and a significant $(\mathrm{P}<0.01)$ reduction in the activity of GSH and SOD in cardiac tissue of disease control animals (Table 3, Table 4, Figure 3, Figure 4).

Animals fed with dietary Phoenix dactylofera found to have decreased MDA and CAT levels and an improvement in GSH and SOD levels which confirms our claim that Phoenix dactylofera has the antioxidant effect in DXR-induced cardiomyopathy (Table 4, Figure 4). Histological examinations demonstrated an altered architecture of the cardiomyocytes of the diseased control animals which were found to be restored in the animals fed with the Phoenix dactylofera (Figures 5(a)-(e)).

\section{Conclusion}

Findings of the research demonstrate that dietary intake of Phoenix dactylofera has the pronounced preventive effect on the cardiotoxicity of doxorubicin. Further administration of nutraceutical has the marked influence on the various parameters of importance related to cardiotoxicity. Hence, therefore, it can be concluded that co-administration of Phoenix dactylofera with diet is well capable of reducing the incidents of cardiotoxicity. 


\section{Acknowledgements}

This work was supported by the grant number 43410001 from the institute of scientific research and revival of Islamic heritage (ISRRIH), Umm Al-Qura University, Makkah, Saudi Arabia.

\section{References}

[1] Cohn, J.N., Ferrari, R. and Sharpe, N. (2000) Cardiac Remodeling-Concepts and Clinical Implications: A Consensus Paper from an International Forum on Cardiac Remodeling. Behalf of an International Forum on Cardiac Remodeling. Journal of the American College of Cardiology, 35, 569. http://dx.doi.org/10.1016/S0735-1097(99)00630-0

[2] Dorn, G.W., Robbins, J. and Sugden, P.H. (2003) Phenotyping Hypertrophy: Eschew Obfuscation. Circulation Research, 92, 1171. http://dx.doi.org/10.1161/01.RES.0000077012.11088.BC

[3] Opie, L.H., Commerford, P.J., Gersh, B.J. and Pfeffer, M.A. (2006) Controversies in Ventricular Remodelling. Lancet, 367, 356. http://dx.doi.org/10.1016/S0140-6736(06)68074-4

[4] Al Farsi, M.A. and Lee, C.Y. (2008) Nutritional and Functional Properties of Dates: A Review. Critical Reviews in Food Science and Nutrition, 48, 877-887. http://dx.doi.org/10.1080/10408390701724264

[5] Al-Shahib, W. and Marshall, R.J. (2003) The Fruit of the Date Palm: Its Possible Use as the Best Food for the Future. International Journal of Food Science and Nutrition, 54, 247-259. http://dx.doi.org/10.1080/09637480120091982

[6] Baliga, R.S., MacAllister, R.J. and Hobbs, A.J. (2011) New Perspectives for the Treatment of Pulmonary Hypertension. British Journal of Pharmacology, 163, 125-140. http://dx.doi.org/10.1111/j.1476-5381.2010.01164.X

[7] Baliga, M.S., Baliga, B.R.V., Kandathil, S.M., Bhat, H.P. and Vayalil, P.K. (2011) A Review of the Chemistry and Pharmacology of the Date Fruits (Phoenix dactylifera L.). Food Research International, 44, 1812-1822. http://dx.doi.org/10.1016/j.foodres.2010.07.004

[8] Hersi, A.S., Alhabib, K.F., AlFaleh, H.F., Al Nemer, K., AlSaif, S., Taraben, A., Kashour, T., Abuosa, A.M. and AlMurayeh, M.A. (2012) Incidence of Ventricular Arrhythmia and Associated Patient Outcomes in Hospitalized Acute Coronary Syndrome Patients in Saudi Arabia: Findings from the Registry of the Saudi Project for Assessment of Acute Coronary Syndrome (SPACE). Annals of Saudi Medicine, 32, 372-377. http://dx.doi.org/10.5144/0256-4947.2012.372

[9] Koura, M.R., Al-Dabal, B.K., Rasheed, P., Al-Sowielem, L.S. and Makki, S.M. (2012) Prehypertension among Young Adult Females in Dammam, Saudi Arabia. East Mediterranean Health Journal, 18, 728-734.

[10] Stewart, D.J., Evans, W.K., Shepherd, F.A., Wilson, K.S., Pritchard, K.I., Trudeau, M.E., Wilson, J.J. and Martz, K. (1997) Cyclophosphamide and Fluorouracil Combined with Mitoxantrone versus Doxorubicin for Breast Cancer: Superiority of Doxorubicin. Journal of Clinical Oncology, 1897-1905.

[11] Erhola, M., Kellokumpu-Lehtinen, P., Metsa-Ketela, T., Alanko, K. and Nieminen, M.M. (1996) Effects of Anthracyclin-Based Chemotherapy on Total Plasma Antioxidant Capacity in Small Cell Lung Cancer Patients. Free Radical Biology and Medicine, 21, 383-390. http://dx.doi.org/10.1016/0891-5849(96)00041-X

[12] Soga, M., Kamal, F.A. and Watanabe, K. (2006) Effects of Angiotensin II Receptor Blocker in Daunorubicin-Induced Cardiomyopathic Rats. International Journal of Cardiology, 110, 378-385. http://dx.doi.org/10.1016/j.ijcard.2005.08.061

[13] Ferreira, A.L., Salvadori, D.M. and Nascimento, M.C. (2007) Tomato-Oleoresin Supplement Prevents DoxorubicinInduced Cardiac Myocyte Oxidative DNA Damage in Rats. Mutation Research, 631, 26-35. http://dx.doi.org/10.1016/j.mrgentox.2007.04.003

[14] Nazeyrollas, P., Prevost, A., Baccard, N. and Manot, L. (1999) Effects of Amifostine on Perfused Isolated Rat Heart and on Acute Doxorubicin-Induced Cardiomyopathy. Cancer Chemotherapy and Pharmacology, 43, 227-232. http://dx.doi.org/10.1007/s002800050888

[15] Myers, C.E., McGuire, W.P. and Liss, R.H. (1977) Adriamycin: The Role of Lipid Peroxidation in Cardiac Toxicity and Tumor Response. Science, 197, 165-167. http://dx.doi.org/10.1126/science.877547

[16] El-Shitany, N.A., El-Haggar, S. and El-desoky, K. (2008) Silymarin Prevents Adriamycin Induced Cardiomyopathy and Nephropathy in Rats. Food and Chemical Toxicology, 46, 2422-2428. http://dx.doi.org/10.1016/j.fct.2008.03.033

[17] Toko, H., Oka, T. and Zou, Y. (2002) Angiotensin II: Type Ia Receptor Mediates Doxorubicin-Induced Cardiomyopathy. Hypertension Research, 25, 597-603. http://dx.doi.org/10.1291/hypres.25.597

[18] Ohkawa, H., Ohishi, N. and Yagi, K. (1979) Assay for Lipid Peroxides in Animal Tissues by Thiobarbituric Acid Reaction. Analytical Biochemistry, 95, 359-64. http://dx.doi.org/10.1016/0003-2697(79)90738-3

[19] Marklund, S. and Marklund, G. (1974) Involvement of the Superoxide Anion Radical in the Autoxidation of Pyrogallol and a Convenient Assay for Superoxide Dismutase. European Journal of Biochemistry, 47, 469-474. http://dx.doi.org/10.1111/j.1432-1033.1974.tb03714.x 
[20] Goormaghtigh, E. and Ruysschaert, J.M. (1984) Anthracycline Glycoside-Membrane Interactions. Biochimica et Biophysica Acta, 779, 271-288. http://dx.doi.org/10.1016/0304-4157(84)90013-3

[21] Olson, H.M., Young, D.M., Prieur, D.J., LeRoy, A.F. and Reagan, R.L. (1974) Electrolyte and Morphologic Alterations of Myocardium in Adriamycin-Treated Rabbits. American Journal of Pathology, 77, 439-454.

[22] Olson, R.D., Mushlin, P.S., Brenner, D.E., Fleischer, S., Cusack, B.J., Chang, B.K. and Boucek Jr., R.J. (1988) Doxorubicin Cardiotoxicity May Be Caused by Its Metabolite, Doxorubicinol. Proceedings of the National Academy of Sciences of the United States of America, 85, 3585-3589. http://dx.doi.org/10.1073/pnas.85.10.3585

[23] Robison, T.W. and Giri, S.N. (1987) Effects of Chronic Administration of Doxorubicin on Heart Phospholipase A2 Activity and in Vitro Synthesis and Degradation of Prostaglandins in Rats. Prostaglandins, Leukotrienes and Medicine, 26, 59-74. http://dx.doi.org/10.1016/0262-1746(87)90152-1

[24] Klugmann, F.B., Decorti, G., Candussio, L., Grill, V., Mallardi, F. and Baldini, L. (1986) Inhibitors of AdriamycinInduced Histamine Release in Vitro Limit Adriamycin Cardiotoxicity in Vivo. British Journal of Cancer, 54, 743-748. http://dx.doi.org/10.1038/bjc.1986.235

[25] Temma, K., Akera, T., Chugun, A., Ohashi, M., Yabuki, M. and Kondo, H. (1992) Doxorubicin: An Antagonist of Muscarinic Receptors in Guinea Pig Heart. European Journal of Pharmacology, 220, 63-69. http://dx.doi.org/10.1016/0014-2999(92)90012-S

[26] Voest, E.E., Van Acker, S.A., Van Der Vijgh, W.J., Van Asbeck, B.S. and Bast, A. (1994) Comparison of Different Iron Chelators as Protective Agents against Acute Doxorubicin-Induced Cardiotoxicity. Journal of Molecular and Cellular Cardiology, 26, 1179-1185. http://dx.doi.org/10.1006/jmcc.1994.1136

[27] Sacco, G., Bigioni, M. and Evangelista, S. (2001) Cardio Protective Effects of Zofenopril, a New Angiotensin-Converting Enzyme Inhibitor, on Doxorubicin-Induced Cardiomyopathy in the Rats. European Journal of Pharmacology, 414, 71-78. http://dx.doi.org/10.1016/S0014-2999(01)00782-8

[28] Pathan, R.A., Singh, B.K. and Pillai, K.K. (2010) Naproxen Aggravates Doxorubicin Induced Cardiomyopathy in Rats. Indian Journal of Pharmacology, 42, 44-49. http://dx.doi.org/10.4103/0253-7613.62411

[29] Zhu, W., Zou, Y. and Aikawa, R. (1999) MAPK Superfamily Plays an Important Role in Daunomycin-Induced Apoptosis of Cardiac Myocytes. Circulation, 100, 2100-2107. http://dx.doi.org/10.1161/01.CIR.100.20.2100

[30] Elberry, A.A., Abdel-Naim, A.B., Abdel-Sattar, E.A., Nagy, A.A., Mosli, H.A., Mohamadin, A.M. and Ashour, O.M. (2010) Cranberry (Vaccinium macrocarpon) Protects against Doxorubicin-Induced Cardiotoxicity in Rats. Food and Chemical Toxicology, 48, 1178-1184. http://dx.doi.org/10.1016/j.fct.2010.02.008

[31] Hsu, H.C., Chen, C.Y. and Chen, M.F. (2014) N-3 Polyunsaturated Fatty Acids Decrease Levels of Doxorubicin-Induced Reactive Oxygen Species in Cardiomyocytes-Involvement of Uncoupling Protein UCP2. Journal of Biomedical Science, 21, 101. http://dx.doi.org/10.1186/s12929-014-0101-3

\section{Submit or recommend next manuscript to SCIRP and we will provide best service for you:}

Accepting pre-submission inquiries through Email, Facebook, LinkedIn, Twitter, etc.

A wide selection of journals (inclusive of 9 subjects, more than 200 journals)

Providing 24-hour high-quality service

User-friendly online submission system

Fair and swift peer-review system

Efficient typesetting and proofreading procedure

Display of the result of downloads and visits, as well as the number of cited articles

Maximum dissemination of your research work

Submit your manuscript at: http://papersubmission.scirp.org/ 